\title{
Newborn Umbilical Cord Care in Parakou in 2013: Practices and Risks
}

\author{
Joseph Agossou1*, Marcelline Hounnou-d'Almeïda², Julien Didier Adédémy1, \\ Alphonse Noudamadjo', Doué Yasmine Gounou N'gobi', Blaise Ayivi² \\ ${ }^{1}$ Department of Mother and Child, Faculty of Medicine, University of Parakou, Parakou, Benin \\ ${ }^{2}$ Department of Mother and Child, Faculty of Health Sciences, University of Aboomey-Calavi, Cotonou, Benin \\ Email: "agossoujoseph@gmail.com
}

Received 6 February 2016; accepted 18 March 2016; published 21 March 2016

Copyright $@ 2016$ by authors and Scientific Research Publishing Inc.

This work is licensed under the Creative Commons Attribution-NonCommercial International License (CC

BY-NC).

http://creativecommons.org/licenses/by-nc/4.0/

(c) (i) () Open Access

\begin{abstract}
Objective: The objective was to study umbilical care practices and risks in Parakou (North Benin). Patients and method: It was a cross-sectional and descriptive study carried out within a community from June 1 to August 31, 2013. It focused on all the infants born at the maternity of Parakou Health Center and their mothers. Results: Two hundred and ten newborns were included i.e. 101 boys and 109 girls. In $80.9 \%$ of cases, inappropriate substances had been applied to umbilical cord. Umbilical cord care quality was adjudged as poor, acceptable and good in $58.6 \%, 31.9 \%$ and $9.5 \%$ of cases respectively. A bacterial umbilical infection had been noted in $59.5 \%$ of newborns. Only 4.8\% had sterile umbilical wound. The commonest bacteria were: Staphylococcus aureus (58.1\%), Staphylococcus saprophiticus (53.3\%), Escherichia coli (44.8\%) and Pseudomonas aeruginosa $(14.3 \%)$. The factors associated with umbilical infection were: low educational status of mother $(\mathrm{p}=$ 0.026), low-income occupation of mother $(p=0.021)$, customary practices to accelerate umbilical cord fall off $(p=0.007)$, short time to cord falling off lower than 6 days $(p=0.015)$. Conclusion: Umbilical cord care involves high risk for bacterial infection in our context. Strong actions must be taken within the community in order to reduce that risk.
\end{abstract}

\section{Keywords}

Umbilical Care Practices, Risks, Newborn, Parakou, Benin

\section{Introduction}

According to the World Health Organization (WHO) estimates, ten thousand newborns die every day, of which ${ }^{*}$ Corresponding author.

How to cite this paper: Agossou, J., Hounnou-d'Almeïda, M., Adédémy, J.D., Noudamadjo, A., N'gobi, D.Y.G. and Ayivi, B. (2016) Newborn Umbilical Cord Care in Parakou in 2013: Practices and Risks. Open Journal of Pediatrics, 6, 124-135. 
$99 \%$ in developing countries. Neonatal infections are the cause of $30 \%$ to $40 \%$ of those deaths [1] [2]. Each year, 520,000 newborns die after severe bacterial infection and a significant proportion of infection-related deaths is associated with umbilical cord infections [3]. In fact, among the acquired bacterial neonatal infections, umbilical cord wound is considered as one of the predominant potential sources of entry of infectious pathogenic microorganisms [4] [5].

Morbidity and mortality related to umbilical cord infections have become rare in developed countries but they are still significant in developing countries. A community-based study carried out in Pakistan in 2011 proved that $21.7 \%$ of the 6904 examined newborns had umbilical infection. During the same study, the incidence of umbilical infections was estimated at 271.4\%o of live births [6]. In 2006 at the Cocody University Teaching Hospital (CHU) in Ivory-Coast, Amorisanni et al. found out that bacterial infections associated with traditional care had a $69.3 \%$ frequency, of which $65.2 \%$ had umbilical origin [7]. In Benin, a retrospective study carried out over 8 years (2002-2009) in the neonatal care unit of the Borgou Regional University Hospital (CHUD-Borgou) allowed to note in 2010 that umbilical infections accounted for $6.1 \%$ of neonatal infections [8]. In Benin in general and particularly in its northern region, customary practices in terms of umbilical care expose newborn to umbilical infection. In order to have a better understanding of the issue so as to contribute to reduce morbidity and mortality due to umbilical infection, the general objective of the current study, initiated within a community in Parakou, was to investigate umbilical cord care practices in the town of Parakou. The specific objectives were:

- To identify the community-based practices of umbilical cord care among newborns.

- To determine, according to well-defined criteria, the proportion of newborns who received adequate umbilical cord care.

- To determine the proportion of newborns bearing bacteria at the umbilical cord and the nature of those bacteria.

- To identify the factors associated with umbilical infection.

\section{Patients and Methods}

It was a cross-sectional and descriptive study with prospective data collection conducted over a three-month period ranging from June 1 to August 31, 2013. The study population consisted of infants born at the maternity of the District Health Center (DHC) of Parakou during the period and their mothers. This health center is a firstlevel structure that performs on average 150 deliveries per month.

Inclusion criteria: all infants born alive at the maternity of the District Health Center of Parakou.

Exclusion criteria: The study did not include all newborns in bad condition at birth and who were referred to the CHUD-Borgou neonatal care unit. Those whose parents did not live in the town of Parakou or those whose parents refused to participate in the study were not recruited.

Sampling: Sampling was done for convenience in relation to the material and financial constraints. Thus, taking into account the criteria of inclusion and exclusion, all newborns delivered in DHC Parakou during the period participated in the study.

Data collection procedure: Some measures were set up within the DHC maternity of Parakou for the identification of newborn and mother's residence. Those measures consisted of a notebook where midwives mentioned date of delivery, name of mother, her full address (area, house, phone number) and any other information likely to help find her residence. Before discharge from maternity, we requested and obtained the consent of each parturient who would like to participate in the study. At birth, an umbilical bandage was performed in each newborn with clean cotton, alcohol and cord stump was wrapped into a compress, the whole protected by an elastic bandage.

After discharge from maternity, data were collected using a questionnaire we drafted and administered to mothers during a visit at home between the $48^{\text {th }}$ and the $96^{\text {th }}$ hour after delivery. That questionnaire specifies practices and umbilical cord care provided to newborn since his birth. Each newborn benefitted from complete clinical examination, careful examination of umbilical wound and bacterial sampling by swabbing. Each mother was given a kit of sterile material (cotton, compress) in order to continue umbilical cord care. After each sample, an adequate umbilical bandage was performed with sterile material. Phone call and home visit were systematically made one week later to inquire about newborn's health condition and time to umbilical cord separation.

At CHUD-Borgou laboratory, samples were cultured in special media to identify bacteria likely to be encountered. 


\subsection{Study Variables}

The dependent variables were quality of umbilical cord care provided to the newborn (excellent, good, acceptable or poor quality of care) and absence or presence of umbilical infection.

The independent variables were socio-demographic (newborn's sex, age of mother, ethnicity, religion, occupation of mother, mother's educational status, parents' socioeconomic status). They are related to different umbilical cord care practices (newborn bathing technique before cord falls off, substances used for cord care, time to umbilical cord falling off, hand washing before care, materials used in umbilical care, person who influenced the choice of practices). The clinical (fever, condition of umbilical wound, time for discharge from maternity) and bacteriological (bacteria encountered in umbilical wound sample) variables were also studied.

\subsection{Definitions of Some Concepts}

\section{$\checkmark$ Quality of care}

Drawing on national documents of standards of care to newborns, the following classification was used as part of this study.

The quality of care was adjudged as excellent when:

- newborn is wiped by means of a clean towel wet with warm water without wetting stump until umbilical cord falls off,

- hands are washed with water and soap before umbilical care,

- cotton wool and compress used are sterile,

- disinfection is done with alcohol alone followed by application of $2 \%$ of aqueous eosin everyday till umbilical cord falls off,

- umbilical cord is kept dry protected by a light bandage.

It is adjudged as good when:

- newborn is wiped with a wet clean towel till umbilical cord falls off,

- hands are washed with water and soap before umbilical care,

- cotton wool and compress used are clean,

- disinfection is done with $70^{\circ}$ alcohol alone with or without application of $2 \%$ aqueous eosin,

- umbilical cord is kept and protected by a light bandage.

It is adjudged as acceptable when:

- newborn is given a bath with plenty of water before umbilical cord falls off,

- hands are washed before care,

- cotton wool and compress used are clean,

- disinfection was done with antiseptics others than alcohol,

- umbilical cord is kept dry with or without bandage.

Eventually, it was adjudged as poor for any other form of care.

\section{$\checkmark$ Classification of parents socioeconomic status}

We used INSAE (official statistics institute) rating criteria to assess socioeconomic status. It was determined by sum of values of the following items: housing, household materials, rolling stock and environmental hygiene. Each parameter will be given a value from 0 to 3; except environment which will be given a value from 0 to 1 . A score $<4$ will be considered as a low level, between 4 and 12 as an average level, and a score $>12$ as a high level [9].

\section{$\checkmark$ Umbilical infection or omphalitis and bacterial colonization}

An umbilical infection or omphalitis was adopted as diagnosis if in addition to the presence of bacteria in the wound, there are redness and discharge of seropurulent fluid or if cord stump is putrid with or without fever.

Colonization is identified if in spite of presence of bacteria in the wound, newborn's general condition is good without sign of apparent infection; umbilical wound does not give off a foul smell and does not discharge pus.

\section{$\checkmark$ Selection of umbilical cord care method}

As regards selection of umbilical cord care method, it is related to the person who influenced that choice. We considered three groups of persons, namely:

- A health worker who may be a doctor, a nurse, a midwife, a nurse assistant who provided advice on umbilical cord care to mother or to her close relatives and friends after delivery or at any other moment.

- Customary practices: this expression encompasses the advices given by a member of mother's family or 
in-laws concerning umbilical cord care.

- Neighbor or third party: when the advice was given by another person.

$\checkmark$ Notions of dry heat and moist heat in umbilical care

Regarding umbilical cord care after it falls off,

- Dry heat refers to application to umbilical wound of an object which previously passed through a source of heat such as lantern, furnace, hot knife and hot stone.

- Moist heat refers to application of hot water to umbilical wound.

\subsection{Data Analysis}

The data collected were coded and entered with Epi info version 3.2. Once audited, those data were transferred to SPSS 19.0 statistical software for the design of crossed tables and statistical tests (Khi Deux, Student and Fisher Sinédécor). Excel software was used on a cross-cutting basis for the processing of some tables and construction of graphics. Significance level or threshold was defined by $\mathrm{p}<0.05$ and confidence $95 \%$ interval.

\subsection{Ethical Considerations}

Approval was obtained from the ethics committee of the Faculty of Medicine of the University of Parakou and the administrative authorities at various levels for carrying out the current study. Parents of target newborns also gave their informed verbal consent. Confidentiality of data collected was guaranteed. During visits to the community, sick newborns identified were attended and provided care.

\section{Results}

\subsection{Sociodemographic Characteristics of the Population Included in the Study}

Of the 260 infants born at DHC/Parakou during the period, 210 were included in the study, 10 were referred to the CHUD-Borgou Neonatal Care Unit, 21 lived outside Parakou, the residences of 17 newborns were not found and 2 mothers had refused to participate in the study. Sex ratio was estimated at 0.92 . Mothers' mean age was 25.8 years \pm 5.32 with extremes ranging from 15 to 45 years. As regards mothers' educational status, 68 (32.4\%) were not enrolled in school, 73 (34.8\%) had primary school level and 69 (32.8\%) had high school level and more. As far as mothers' occupation is concerned, 81 (38.6\%) were resellers, 50 (23.8\%) were craft workers or caterers, 41 (19.5\%) were housewives, 21 (10\%) were high school or university students and 17 (8.1\%) were civil servants. Concerning socioeconomic status, 101 (48.1\%) of newborns were from families with low socioeconomic status. As far as religion is concerned, 127 (60.5\%) of the mothers were Muslims, 77 (36.7\%) were Christians and 6 (2.8\%) were followers of endogenous religions. Table 1 shows the different ethnic groups to which newborns belonged.

\subsection{Length of Stay of Mothers and Their Children at CSC/Parakou after Delivery}

The length of stay of newborns at the maternity of DHC/Parakou was less than six hours among 15 (7.1\%), between six and twelve hours in 127 (60.5\%) and higher than twelve hours in 68 (32.4\%). Any of them has spent more than 24 hours at health center after birth.

Table 1. Distribution of newborns according to their ethnic group.

\begin{tabular}{ccc}
\hline & Number & Percentage (\%) \\
\hline Dendi and related ethnic groups & $\mathbf{4 5}$ & $\mathbf{2 1 . 4}$ \\
Fon and related ethnic groups & $\mathbf{4 3}$ & $\mathbf{2 0 . 5}$ \\
Bariba and related ethnic groups & $\mathbf{4 0}$ & $\mathbf{1 9}$ \\
Yoruba and related ethnic groups & 33 & 15.7 \\
Lokpa and related ethnic groups & 22 & 10.5 \\
Ottamari and related ethnic groups & 13 & 6.2 \\
Fulani and related ethnic groups & 9 & 4.3 \\
Other ethnic groups & 5 & 2.4 \\
Total & $\mathbf{2 1 0}$ & $\mathbf{1 0 0 . 0}$
\end{tabular}

${ }^{*}$ The other ethnic groups were: Hausa 1, Igbo 2 and Sola 1. 


\subsection{Panorama of Substances Used for Umbilical Cord Care among Newborns}

\section{$\checkmark$ Before umbilical cord falling off}

Before umbilical cord falls off, 195 (92.9\%) of newborns had been given bath with a lot of water. The others were cleaned with a wet towel until cord falls off. Seventy-three percent (153) of mothers claimed to have washed simply hands before providing umbilical cord care and 57 (27\%) of them did not wash hands before care. After newborn's toilet, 104 (49.5\%) of the mothers cleaned umbilical cord with clean cotton. The other mothers used strips of fabric, cleaning or wiping rags, towels and cotton buds. Table 2 indicates distribution of newborns according to substances applied to umbilical cord before it falls off.

Herbs and by-products were used in a proportion of $13.8 \%$. These were $2.8 \%$ of leaves of Synedrella nodiflora, leaves of Calotropis procera or Apple of Sodome (globular berry) in $1.4 \%$ of cases. Sap of Calotropis procera was used for 12 newborns (5.7\%). As regards alcohol alone, it was used by 34 mothers (16.1\%). The association of alcohol plus aqueous eosin was used by 6 mothers (2.8\%). In 170 newborns (80.9\%), inappropriate or harmful substances had been applied to umbilical cord. One substance was applied in 91 newborns (43.3\%) and two substances simultaneously in 89 newborns (42.4\%). For 23 newborns (10.9\%), more than two substances were applied. No substance was applied to the umbilical cord of seven (07) newborns (3.3\%). The frequency of substances application to umbilical cord stump was twice a day in 59\% of cases, higher than two times a day in $26.2 \%$ of cases and once a day in $14.8 \%$ of cases. The mean time for umbilical cord falling off was 4.27 days \pm 1.62 with extremes ranging from 2 to 9 days. For 177 (84.3\%) of newborns, umbilical cord fell off before the 6th day of life, of which $5.7 \%$ before 72 hours of life.

\section{$\checkmark$ After umbilical cord falling off}

Table 3 shows distribution of newborns according to the different practices used after umbilical cord falls off.

\subsection{Quality of Umbilical Cord Care Performed in the 210 Newborns According to Our Criteria and Persons Who Influenced Choice of Umbilical Cord Care Practice}

According to our criteria, 123 (58.6\%) had received care of poor quality, 67 (31.9\%) of acceptable quality and

Table 2. Distribution of newborns according to substances applied to umbilical cord before it falls off.

\begin{tabular}{ccc}
\hline & Number & Percentage (\%) \\
\hline Alcohol & $\mathbf{8 1}$ & $\mathbf{3 8 . 6}$ \\
Cooking salt & 57 & 27.1 \\
Petroleum jelly & 50 & 23.8 \\
Shea Butter & 41 & 19.5 \\
Toothpaste & 35 & 16.6 \\
Plant sap & 17 & 8.1 \\
Maggi food cube & 12 & 5.7 \\
Herbal mixtures & 12 & 5.7 \\
2\% aqueous eosin & 9 & 4.3 \\
No application & 7 & 3.3 \\
Other substances & 26 & 12.4 \\
\hline
\end{tabular}

${ }^{*}$ The other substances were: perfume $=6$, talc $=5$, ash $=4$, palm kernel oil $=3$, menthol-containing balm $=2$, white chalk $=1$, wasp nest clay $=1$, ash + saliva + cauterization $=1$, powder of basted shea nut $=1$, penicillin ointment $=1$, betadine $=1$. ${ }^{* *}$ It is important to note that one newborn may benefit from the application of many substances at once during umbilical care.

Table 3. Distribution of newborns according to the different practices used after umbilical cord falls off.

\begin{tabular}{ccc}
\hline & Number & Percentage (\%) \\
\hline Dry heat & $\mathbf{9 0}$ & $\mathbf{4 2 . 8}$ \\
Moist heat & 66 & 31.4 \\
Shea butter & 51 & 24.3 \\
Antiseptics & 17 & 8.1 \\
Others $^{*}$ & 13 & 6.2 \\
\hline
\end{tabular}

${ }^{*}$ The other substances applied were: palm kernel oil 4, spices 2 , talc 3 , shea butter powder 1 , petroleum jelly 1 , nivaquine ${ }^{\mathrm{R}}+$ lyophilized injectable penicillin 1. 
20 (9.5\%) of good quality. No mother has applied care of excellent quality to her child. As regards choice of umbilical cord care practice, the mothers interviewed stated that they refer to custom in 143 (68.1\%) of cases, to health workers' advices in 39 (18.6\%) of cases and to neighbors' advices in 28 (13.3\%) of cases.

\subsection{Profile of Bacteria Encountered in Newborns' Umbilical Wounds}

After bacterial culture of umbilical wound samples, 14 types of bacteria were found out. Those bacteria were alone or in association. Table 4 provides a summary of bacteria encountered by frequency order.

\subsection{Clinical Condition of Umbilical Wounds during Our Visit}

In 72 newborns (34.3\%), umbilical cord was very malodorous or fetid while in 131 of them (62.4\%), there was fluid drainage in the umbilical wound, including $65 \%$ of seropurulent and $35 \%$ of serohematic fluid. Besides, among all the newborns examined during our home visit, 2 had fever and 3 had hypothermia. Taking into account clinical signs and bacteriological results, umbilical infection was diagnosed in 125 (59.5\%) of newborns, bacterial colonization in 75 (35.7\%) and 10 (4.8\%) had sterile umbilical wound.

\subsection{Factors Associated with Umbilical Infection}

The factors associated with umbilical infection were: low pay occupation of mother $(\mathrm{p}=0.021$; $\mathrm{RR}=2.39$; CI: 1.26 - 4.52), customary practices for accelerating cord falling off ( $p=0.007$; RR $=2.15$; CI: $1.43-3.22)$, short time to umbilical cord falling off lower than 6 days ( $=0.015$; RR = 1.76; CI: $1.19-2.59$ ), mother's low educational status i.e. she is illiterate or has primary school level ( $\mathrm{p}=0.026$; $\mathrm{RR}=1.36$; CI: $1.08-1.72$ ). In contrast, using aqueous eosin has a protective effect for it does not facilitate the occurrence of umbilical infection with 0.034 p-value; $\mathrm{RR}=0.29$ and 0.10 - $0.85 \mathrm{CI}$.

\section{Discussion}

\subsection{Sociodemographic Characteristics of Population Included in the Study}

The female predominance noted in the current study is similar to the one found out within Parakou district population during the General Population and Housing Census (RGPH 4) conducted in 2013 in Benin [10]. Our finding is similar to the one of Abhulimhen-Iyoha et al. who studied practices of umbilical cord care in newborns in 2009 at the Benin City University teaching hospital [11] [12]. In contrast, male sex predominated in another study on newborn umbilical cord care carried out by Joel-Medewase et al. in Osun State (South-west Nigeria) in 2008; sex ratio was 1.1 [13]. As regards mothers' age, it varied from 15 to 45 years with a mean of

Table 4. Frequency by descending order of bacteria encountered in umbilical samples.

\begin{tabular}{ccc}
\hline & Number & Percentage (\%) \\
\hline Staphylococcus aureus & $\mathbf{1 2 2}$ & $\mathbf{5 8 . 1}$ \\
Staphylococcus saprophiticus & $\mathbf{1 1 2}$ & $\mathbf{5 3 . 3}$ \\
Escherichia coli & $\mathbf{9 4}$ & $\mathbf{4 4 . 8}$ \\
Pseudomonas aeruginosa & $\mathbf{3 0}$ & $\mathbf{1 4 . 3}$ \\
Staphylococcus epidermidis & $\mathbf{2 0}$ & $\mathbf{9 . 5}$ \\
Klebsiella pneumoniae & $\mathbf{1 9}$ & $\mathbf{9}$ \\
Klebsiella azeniae & 14 & 6.7 \\
Proteus mirabilis & 13 & 6.2 \\
Proteus vulgaris & 5 & 2.4 \\
Proteus Rettegeri & 4 & 1.9 \\
Yeasts & 4 & 1.9 \\
Klebsiella hymoleromotus & 2 & 1 \\
Proteus morgani & 1 & 0.5 \\
Streptococcus agalactiae & 1 & 0.5 \\
\hline
\end{tabular}


$25.80 \pm 5.32$ years. This relative young age of mothers was also reported by several Nigerian researchers. Abhulimhen-Iyoha et al. reported a mean age of $29.10 \pm 4.91$ years [11] [12]. As far as Opara et al. are concerned, they reported that $62.9 \%$ of mothers were aged less than 30 years during a study on newborn umbilical cord care practices in Bayelsa State in the Niger Delta region (Nigeria) in 2011 [14]. More than half of children's mothers did not attended school or had only primary school level. Joel-Medewase et al. [13] had obtained a proportion less elevated than our (44\%). Another study carried out in Nigeria by Ambe et al. on newborn umbilical cord care revealed that $64 \%$ of children's mothers did not attend school; this corresponded to the double of the proportion of unschooled mothers in our study [15]. As regards mothers' occupation, our findings are in consonance with those of Abhulimen-Iyoha et al. who identified 38\% of resellers, $26 \%$ of craft workers and $13.7 \%$ of housewives [11] [12]. Several research works performed in the sub-region by different authors on newborn traditional care practices disclosed that housewives were the most represented, thus disagreeing with our study findings [7] [15]. As regards mothers' socioeconomic status, more than half of them had low status. That low socioeconomic status was also reported by Abhulimhen-Iyoha et al. and Opara et al. in respective proportions of 46.8\% and 46.2\% [11] [12] [14]. The low socioeconomic status noted in mothers of children included in the study is the characteristic feature of population poverty level in the District of Parakou. The high rate of jobless mothers or mothers exerting poorly paid jobs associated with significant proportion of low socioeconomic status places mother/child couple in a situation of precariousness and vulnerability. As regards sociocultural aspect, the distribution of sociolinguistic and religious groups in our study is in agreement with the one of the 2013 General Population and Housing Census conducted in the town of Parakou [10].

\subsection{Umbilical Cord Care Practices and Substances Used}

Several practices were identified in our study and they are involved in all levels of newborn care. As regards newborn toilet, it consisted of bath with a lot of water for the majority of newborns upon discharge from the maternity. This toilet method which is not in keeping with WHO 1999 recommendations [16] may be due to some cultural factors. In fact, some African ethnic groups consider vernix caseosa as a sperm accumulation in the father [17]. The child would be born with on his skin sperm marks, blood and impurities that should be cleaned with a lot of water. According to some popular beliefs from "Baatonu" ethnic group (North-Benin), newborn repeated baths would have the power to make him put on weight. Newborns were thus given bath many times a day and some of them after each change. Those repeated baths keep moisture in the umbilical cord which is a source of rot and umbilical infection and also expose newborn to risk of hypothermia. Concerning the use of sterile material for cord care, it was not observed in our study. Actually, umbilical cord care practiced at the CSC maternity of Parakou was performed with non-sterile cotton and gauze bandage sold in public pharmacies or provided at the health center's pharmacy. The antiseptic used was $70^{\circ}$ alcohol without aqueous eosin as a dryer. This remark was also made by Abhulimhen-Iyoha et al. and Ambe et al. in Nigeria [11] [12] [15]. The use of sterile materials was encountered only in $0.8 \%$ of newborns of Abhulimhen-Iyoha et al. series [11] [12]. This is most noted in Sub-Sahara African countries where ignorance of populations who are often illiterate and do not have any knowledge of notion of pathogens likely to infect umbilical wound with death risk for the newborn. This observation is also related to lack of information, education and communication (IEC) sessions for health condition of mothers-to-be during antenatal care and after delivery. The non-use of cotton and sterile compresses during umbilical care is due to improper implementation of national guidelines related to newborn care [18]-[20]. This is an obstacle to the development of quality assurance that was so much exalted for many years in the care provision plan at all levels of the health pyramid in Benin. As regards substances used during umbilical care, this study enabled us to identify a wide range of substances used by mothers. These were antiseptics, cooking products, body care products, and herbal mixtures. The use of those substances was also reported by many African researchers such as Abhulimhen-Iyoha et al., Opara et al., Ambe et al. and Medewase et al. in Nigeria, Amorissani et al. in Côte- d'Ivoire and Koffi et al. in Togo [7] [11]-[15] [21]. The poor use of eosin by mothers in the study (2.85\%) may be due to the ignorance of its drying effect by populations and even by health workers. The dirty character of this substance was mentioned by some mothers as the reason why they do not use it. Acoording to the World Health Organization, some antiseptics like $70^{\circ}$ alcohol have been recommended in newborn's umbilical cord [16]. The use of that antiseptic alone was identified only in $16.2 \%$ of cases. Abhulimhen-Iyoha et al. and Opara et al. reported alcohol in proportions higher than our respectively in $20.5 \%$ and $29 \%$ of cases [11] [12] [14]. This proportion of use of alcohol alone was increased fivefold in the study of 
Medewase et al. while for Ambe et al., only 8.5\% of children of the series benefitted from alcohol use for umbilical cord care [13] [15]. The best performances in use of alcohol alone for umbilical cord care encountered in the study carried out by Medewase et al., were obtained thanks to the efficient implementation of IEC sessions by health workers concerning newborns umbilical cord care [13]. Besides, delayed cord falling off associated with alcohol use may also explain some mothers' reluctance to limit themselves to its single use for umbilical cord care for the benefit of their children [22]-[24]. It is probably the reason why other substances are applied after disinfection with alcohol. In fact, Shoaeib et al., during a comparative study of three umbilical cord care methods in Alexandria (Egypt) in 2005, found out that the mean time of umbilical cord falling off was longer in the group using alcohol (6.4 \pm 2.4 days) compared to dry care ( $4.7 \pm 1.9$ days), and traditional care (3.4 \pm 0.7 days) [22]. As well, in another comparative study of three care methods at the Shuang Ho university hospital in Taipei in 2008, Liu et al. also reported that cord falling off time was shorter in the group using salicylic sugar powder compared to groups using dry care and alcohol-based care [23]. But the decision to make umbilical cord fall off within a record time must not be achieved at any cost without taking into account child well-being.

As regards other substances applied to umbilical cord in our study, some of them would have chemical and medicinal properties, but the evidence of their antiseptic properties was not demonstrated scientifically. Those substances were used by mothers on the basis of real or reported experiences. The use of cooking salt and ash during newborn umbilical cord care would cause a faster umbilical cord falling off. Traditionally, ash is used for preparation of caustic soda. It is the corrosive effect of that ash that would facilitate quick falling off of umbilical cord. The antiseptic and refreshing properties of peppermint essential oil may explain the application of substances containing by-products of that plant such as toothpaste and "mentholatum" to umbilical cord. Besides, the moisturizing, soothing and healing properties of the butter and other cosmetics containing she butter may justify its use. The external use of Calotropis procera latex as antiseptic and healing substance was reported by Nacoulma et al. in 1996 during a study on medicinal plants and traditional medicinal practices in Burkina Faso [25]. Similarly, the use of Synedrella nodiflora in injuries or lesions with anti-hemorrhagic effect was reported by Konan et al. in 2011 in Ivory-Coast in a study on the chemical composition of essential oils extracted from the leaves of that plant [26]. Despite their medicinal properties and their potential effect on cord wound healing, the use of those substances remains a source of infection because of lack of hygiene in their use. This lack of hygiene is related to preparation and storage process and especially to the application to that wound. It is important to mention that in addition to the infection risk associated with those substances, there are adverse effects, particularly the ones of Calotropis procera which has irritating properties [27]. Some researchers reported that in addition to the infection risk associated with those substances, they would have toxic effects [14].

After umbilical cord falling off, the dry or moist application of hot substances to umbilical wound predominated in our study. In fact, some mothers apply to umbilical wound strips of fabric lightly wet previously put in contact with a source of heat. Others apply directly to the base of umbilical cord a metal such as a knife raised to high temperature after being put in burning charcoal. This form of traditional cauterization is hazardous for newborn's health. The use of heat sources to heal wounds is a current traditional practice in Benin. This may be due to heat property to eliminate germs. However, the temperature of water or tool applicable to skin must be low enough compared to the one required for eliminating a germ. That practice may be improved by using a clean fabric associated with simple hand washing with clean water and soap. But it entails a potentially high risk of burn for the newborn. That practice was also reported by Medewase et al. in a research work where $75.5 \%$ of the study populations apply that method like in our study [13]. As well, traditional cauterization practice aims to separate stump from umbilical cord in record time. That traditional cauterization associated with application of corrosive substances to the base of stump may explain why most newborns of our series had their cords fallen off before five days of life which are a record (4.27 days \pm 1.62 ).

It is obvious that newborn contamination risk is high if immediate environment of the latter is unhealthy. Quality of hand washing before umbilical cord care is a datum to be considered. In the current study, about three out of four mothers (73.3\%) claimed to wash hands before umbilical cord care. However, six out of ten newborns had umbilical infection and only one out of twenty newborns of our series had sterile cord wound. Simple hand washing by using handcrafted traditional soft soap made liquid may reduce risk for umbilical cord infection in our context. A study on newborn home care practices carried out by Darmstadt et al. in 2007 [28] in a rural area of Egypt pointed out a proportion of mothers who use to wash hands before administering care to newborn lower than our (57\%) [29]. The findings of the current study are lower than the ones of Abhulimhen-Iyoha et al. who found out that $86.9 \%$ of mothers washed hands before umbilical cord care [11] [12]. It is 
important to note that in terms of umbilical cord care at birth in developing countries, no consensual guideline focused on factual basis has been developed by the World Health Organization. In fact, a meta-analysis conducted by Zupan et al. and focused on 21 trials (8959 participants) mostly done in high-income countries, neither systemic infection nor death was observed in the studies reviewed. No significant difference was demonstrated between cord care with antiseptics and care by natural drying or with placebo. Several other studies led to the same conclusion [30]-[32]. Like in this study, Mullany et al. evaluated in the South of Nepal the community-based risk factors for umbilical cord infection in newborn and found out that risk infection rates were $29 \%$ and $62 \%$ respectively among newborns receiving topical applications of mustard oil and among those receiving application of other potentially unclean/harmful substances [33].

Based on the findings of facts-focused research on umbilical care at birth, the American Academy of Pediatrics (AAP) recommended since 2010 up to now dry umbilical cord care after birth without systematic application of topical antiseptic agents [5] But it is important to note that for the implementation of that recommendation in countries with limited resources countries, it is necessary to take minimum hygienic measures including washing hands with water and soap, ensure clean and safe delivery and avoid application of inappropriate or harmful substances to umbilical cord stump.

\subsection{Quality of Umbilical Cord Care Practiced by Health Workers and Mothers}

As far as care quality is concerned, it was adjudged as good in only one out of ten newborns. No excellent practice of umbilical cord care for newborns was found out in the current study since guidelines related to newborn care were not complied with, even at the DHC maternity of Parakou. Moreover, newborns' discharge from maternity was very early, sometimes before 6 hours of life while national standards require discharge from maternity after 72 hours of life [18]-[20]. This reality may be a handicap to mothers' good counseling by the health staff on umbilical care. In fact, only one out five mothers benefitted from advices given by a health worker on how providing umbilical cord care. This lack of information from health workers and the non-existence at Parakou DHC of a mechanism dedicated to give mothers information on best practices of umbilical cord care may lead the latter to use customary practices. Abhulimhen-Iyoha et al. reported a rate of good practices (20.5\%) similar to ours [11] [12].

As regards umbilical cord infection, it occurred in 3 out 5 newborns in the current study. Amorissani et al. found out a rate similar to ours i.e. a rate of $65.2 \%$ of the study population [7]. The relatively high incidence of umbilical infection encountered in the current study requires seeking appropriate means for reducing that frequency. In fact, several researchers proved that it is possible to reduce drastically that phenomenon by implementing a sustained campaign within the communities and by ensuring capacity building for maternities' caregivers in umbilical cord care standards at birth. These actions permitted to reduce the incidence of umbilical infections from $21.7 \%$ [6] to $19 \%$ [14] and from $13 \%$ [29] to 5.5\% [33]. On the basis of these data provided by literature, it is thus possible to reduce the incidence of umbilical infection in Benin.

\subsection{Bacteria Encountered in Newborns' Umbilical Samples}

Concerning the bacteria which cause those umbilical infections, the predominance of positive-Gram bacteria identified was also reported by Mir et al. [6]. There is a discrepancy between this finding and the one of an in-hospital study on omphalitis conducted in India by Faridi et al. in 1993. That study reported a predominance of Gram-negative bacteria [26]. As regards the number of bacteria identified per sample, there is a contrast between our findings and those obtained by Mir et al. who found out the presence of one bacterium in $69 \%$ of samples and several bacteria in $30.7 \%$ [6]. The distribution of the main bacteria in the current study is similar to the one reported in 2004 by Sawardekar during a study focused on omphalitis spectrum in the newborn in Oman and in whom the commonest bacteria were: Staphylococcus aureus, Escherichia coli, Klebsiella spp. [34]. Mir et al. isolated the following bacteria in the exudates of umbilical cord wound: Staphylococcus aureus (52\%), Streptococcus pyogenes or beta hemolytic (18\%), Streptococcus agalatictiae (10\%), Pseudomonas spp (10\%), Aeromonas spp (3.2\%), Klebsiella (2\%). These findings are distinct from ours because of the study method used. Actually, in their study, bacterial sample collections had not been systematic for all newborns. Samples were collected when newborn showed infection signs such as periumbilical redness, pus discharge or abdominal bloating [6]. Staphylococcus aureus was the commonest bacterium in the umbilical cord followed by Staphylococcus saprophiticus, Escherichia coli and Pseudomonas aeruginosa. The presence of Pseudomonas aeruginosa 
which is normally a hospital-acquired germ in the umbilical wound must raise concerns as regards quality of umbilical cord care provided by health workers of DHC/Parakou maternity.

\subsection{Factors Associated with Umbilical Infection}

Several factors were associated with umbilical cord infection. Among them, the time of umbilical cord falling off had an influence on infection occurrence. This may be due to the application of aggressive and septic substances likely to separate umbilical cord within 48 hours. This ever quick falling off of umbilical cord exposes newborn to bleeding and infection risk. Besides, stoppage of care upon umbilical cord falling off reported by one out of 5 mothers further exposes that wound to infection risk. Umbilical infection is especially associated with substances applied to umbilical cord stump. Use of eosin appears as a protective factor against umbilical infection. There is no statistically significant relationship between use of a particular substance and occurrence of umbilical infection cord. The infection would be most associated with hygienic measures related to newborn care such as hand washing and preparation and storage conditions of the said substances. Opara et al. also concluded that the application of inappropriate substances is a risk for infection [14]. As well, during a community-based study carried out in Nepal Mullany et al. reported that umbilical cord infection was more common in newborns who received care based on potentially septic substances [33]. In the current study, umbilical infections were most encountered in the group of newborns who received care based on customary practices and counseling from third party $(\mathrm{p}=0.011)$.

\section{Conclusion}

This study was conducted in the one of the twelve public and faith-based maternity of Parakou and having covered only three months of 2013, which did not allow drawing formal conclusions on the entire town. It is then necessary to carry out another large study that addresses the deficiencies listed above. However, the current study has demonstrated that approximately two out of three infants born at DHC/Parakou received umbilical care of poor quality. It also permitted to identify the substances and practices ordinarily used for that purpose within families. Eventually, this research work addresses the infection risk incurred by newborns and bacteria identified in umbilical wounds. Moreover, this research work points out the lack of training of health workers and of information available to mothers in the field of appropriate umbilical care practice.

\section{Conflict of Interests}

No conflict of interest.

\section{References}

[1] Labie, D. (2005) Le scandale des quatre millions de morts néonatales chaque année: Bilan et actions possibles. Médecine/Sciences, 21, 768-771. http://dx.doi.org/10.1051/medsci/2005218-9768

[2] The WHO Young Infants Study Group (1999) Bacterial Etiology of Serious Bacterial Infections in Young Infants in Developing Countries: Results of a Multicenter Study. The Pediatric Infectious Disease Journal, 18, S17-S22. http://dx.doi.org/10.1097/00006454-199910001-00004

[3] Blencowe, H., Cousens, S., Mullany, L.C., Lee, A.C., Kerbert, K., Wall, S., et al. (2011) Clean Birth and Postnatal Care Practices to Reduce Neonatal Deaths from Sepsis and Tetanus: A Systematic Review and Delphi Estimation of Mortality Effect. BMC Public Health, 11, S11. http://dx.doi.org/10.1186/1471-2458-11-S3-S11

[4] Charbet, N. (2012) Les soins du cordon dans les pays en voie de développement. Masson, Paris.

[5] Whitmore, J.M. (2010) Newborn Umbilical Cord Care: An Evidence Based Quality Improvement Project. Doctor of Nursing Practice (DNP) Projects, Paper 13

[6] Mir, F., Tikmani, S.S., Shalkoors, S., Warraich, H.J., Sultana, S., Ali, S.A., et al. (2011) Incidence and Etiology of Omphalitis in Pakistan: A Community-Based Cohort Study. Journal of Infection in Developing Countries, 5, 828-833.

[7] Amorissanni, M.F., Kouakou, C., Dainguy, E., Ouattara, Z., Houenou-Agbo, Y. and Kouamé-Konan, J. (2006) Morbidité et mortalité liées aux soins traditionnels chez les nouveaux nés au CHU de Cocody a Abidjan. Cahier Santé Publications, 5, 68-75.

[8] Noudamadjo, A., Adedemy, J.D. and Agossou, J. (2011) Part des omphalites dans les infections néonatales au Centre Hospitalier Départemental du Borgou à Parakou. Abstracts XI Congrès de la SGOBT (Société de Gynécologie Obstétrique 
du Bénin et du Togo), Lomé, 23-25 Novembre 2011, 59-62.

[9] Institut National de la statistique et de l'analyse économique (INSAE) [Bénin] et Macro International Inc. (2007) Enquête démographique et de santé (EDSB-III)-Bénin 2006. Institut National de la statistique et de l'analyse économique Bénin et Macro International Inc., Claverton, Maryland, USA, 492 p.

[10] Institut National de la statistique et de l’Analyse Economique (2013) Troisième Recenspermt Général de la Population et de l'Habitation (RGPH4) Juin 2013: Résultats provisoires. 8 p.

[11] Abhulimhen-Iyoha, B.I. and Ibadin, M.O. (2012) Determinants of Cord Care Practices among Mothers in Benin City, Echo State, Nigeria. Nigerian Journal of Clinical Practice, 15, 210-213. http://dx.doi.org/10.4103/1119-3077.97320

[12] Abhulimhen-Iyoha, B.I. and Ibadin, M.O. (2011) Cord Care Practices among Mothers Attending Immunization Clinic at the University of Benin Teaching Hospital, Benin City. Nigeria Journal Paediatrics, 38, 104-108. http://dx.doi.org/10.4314/njp.v38i3.72262

[13] Joel-Medewase, V.I., Oyedeji, O.A., Elemile, P.O. and Oyedeji, D.A. (2008) Cord Care Practices of South Western Nigerian Mothers. International Journal of Tropical Medicine, 3, 15-18.

[14] Opara, I.P., Jaja, T. and Dotimi, A.-H. (2012) Newborn Cord Care Practices amongst Mothers in Yenagoa Local Government Area, Bayelsa State, Nigeria. International Journal of Clinical Medicine, 3, 22-27. http://dx.doi.org/10.4236/ijcm.2012.31004

[15] Ambe, J.P., Bello, M., Yahaya, S.J. and Omotora, B.A. (2009) Umbilical Cord Care in Konduga Local Government Area of Borno State North-Eastern Nigeria. International Journal of Tropical Medicine, 5, No. 2.

[16] World Health Organization (1999) Care of the Umbilical Cord: A Review of the Evidence.

[17] Vincke, E. (1991) Liquides sexuels féminins et rapports sociaux en Afrique centrale. Anthropologie et Sociétés, 15, 167-188. http://dx.doi.org/10.7202/015181ar

[18] OMS/USAID/BENIN (2005) Soins essentiels aux nouveau-nés: Manuel technique de base. Février, 40 p.

[19] République du Benin, Ministère de la Santé (2012) Normes de soins en pédiatrie. 93 p.

[20] Ministère de la Santé Benin (2012) Prise en charge de la mère et du nouveau-né dans la communauté: Ce que les familles doivent savoir. $42 \mathrm{p}$.

[21] Koffi, K.S., Balaka, B., Agbo, A., Agbèrè, A.D., Gbadoé, A.D. and Atakouma, D.Y. (2012) Soins traditionnels donnés aux nouveau-nés et nourissons dans le district sanitaire de Kloto (Togo). Journal de la Recherche Scientifique de l'Universite de Lome, 14, 27-37.

[22] Shoaeib, F.M., All, S.A. and EL-Barrawy, M.A. (2005) Alcohol or Traditional Methods versus Natural Drying for Newborn's Cord Care. The Journal of the Egyptian Public Health Association, 80, 169-201.

[23] Liu, M.F., Lee, T.Y., Kuo, Y.L. and Lien, M.C. (2012) Comparative Effects of Using Alcohol, Natural Drying, and Salicylic Sugar Powder on Umbilical Stump Detachment of Neonates. Journal of Perinatal \& Neonatal Nursing, 26, 269-274. http://dx.doi.org/10.1097/JPN.0b013e318261ca33

[24] Hsu, W.C., Yeh, L.C., Chuang, M.Y., Lo, W.T., Cheng, S.N. and Huang, C.F. (2010) Umbilical Separation Time Delayed by Alcohol Application. Annals of Tropical Paediatrics, 30, 219-223. http://dx.doi.org/10.1179/146532810X12786388978643

[25] Ouédréogo-Nacoulma, O.G. (1996) Plantes médicinales et pratiques médicinales traditionnelles au Burkina Faso. Cas du plateau central. Thèse de doctorat ès sciences naturelles, Ouagadougou, 158 p.

[26] Konan, N.S., Kouamé, B.A., Mamyrbekova-Békro, J., Konan, K.M. and Békro, Y.A. (2011) Composition Chimique par GS/SM des huiles essentielles extraites des feuilles de Mikania cordota (BURM.F.) B.L. Robinson et Synedrella nodiflora (L) Gaertn. Bulletin de la Société Royale des sciences de Liège, 80, 846-853.

[27] Louhoues, E.E., Tiahou, G.G., Monde, A.A., Djinhi, J. and Sess, E.D. (2006) Propriétés toxicologiques aiguës du latex de Calotropis procera chez le rat. Pharmacopée Médicinale Traditionnelle Africaine, 14, 187-199.

[28] Darmstadt, G.L., Hussein, M.H., Winch, P.J., Haws, R.A., Lamia, M., El Said, M.A., et al. (2007) Neonatal Home Care Practices in Rural Egypt during the First Week of Life. Tropical Medicine \& International Health, 12, $783-797$. http://dx.doi.org/10.1111/j.1365-3156.2007.01849.x

[29] Mullany, L.C., Faillace, S., Tielsch, J.M., Stolzfus, R.J., Nygaard, K.E., Kavle, J.A., et al. (2009) Incidence and Risk Factors for Newborn Umbilical Cord Infection on Pemba Island Zanzibar, Tanzania. The Pediatric Infectious Disease Journal, 28, 503-509. http://dx.doi.org/10.1097/INF.0b013e3181950910

[30] Zupan, J., Garner, P. and Omari, A.A.A. (2007) Topical Umbilical Cord Care at Birth. Cochrane Database of Systematic Reviews, Issue 4, Article ID: CD001057. http://dx.doi.org/10.1002/14651858.CD001057.pub2

[31] Bautista, R.M.M., Mantaring III, J.B., Uy, M.E.V. and Senen, K.A.A. (2010) Umbilical Cord Antiseptics for Preventing Sepsis and Death among Newborns (Protocol). Cochrane Database of Systematic Reviews, Issue 8, Article ID: CD008635. http://dx.doi.org/10.1002/14651858.CD008635 
[32] Imdad, A., Bautista, R.M.M., Senen, K.A.A., Uy, M.E.V., Mantaring III, J.B. and Bhutta, Z.A. (2013) Umbilical cord antiseptics for preventing sepsis and death among newborns (Review). Cochrane Database of Systematic Reviews, Issue 5, Article ID: CD008635. http://dx.doi.org/10.1002/14651858.CD008635.pub2

[33] Mullany, L.C., Darmstadt, G.L., Katz, J., Khatry, S.K., Leclerq, S.C., Adhikari, R.K., et al. (2007) Risk Factors for Umbilical Cord Infection among Newborns of Southern Nepal. American Journal of Epidemiology, 165, $203-211$. http://dx.doi.org/10.1093/aje/kwj356

[34] Sawardekar, K.P. (2004) Changing Spectrum of Neonatal Omphalitis. The Pediatric Infectious Disease Journal, 23, 22-26. http://dx.doi.org/10.1097/01.inf.0000105200.18110.1e 